\title{
Formation and degradation of lipid droplets in human adipocytes and the expression of aldehyde oxidase (AOX)
}

\author{
Hans Heid ${ }^{1} \cdot$ Ralf Zimbelmann ${ }^{1} \cdot$ Yvette Dörflinger $^{1} \cdot$ Steffen Rickelt $^{1,2}$ \\ Published online: 19 December 2019 \\ (C) The Author(s) 2019
}

\begin{abstract}
Lipid droplet (LD) binding proteins in mammary glands and in adipocytes were previously compared and striking similar sets of these specific proteins demonstrated. Xanthine oxidoreductase (XOR) together with perilipins and the lactating mammary gland protein butyrophilin play an important role in the secretion process of LDs into milk ducts. In contrast, in adipose tissue and in adipocytes, mainly perilipins have been described. Moreover, XOR was reported in mouse adipose tissue and adipocyte culture cells as "novel regulator of adipogenesis". This obvious coincidence of protein sets prompted us to revisit the formation of LDs in human-cultured adipocytes in more detail with special emphasis on the possibility of a LD association of XOR. We demonstrate by electron and immunoelectron microscopy new structural details on LD formation in adipocytes. Surprisingly, by immunological and proteomic analysis, we identify in contrast to previous data showing the enzyme XOR, predominantly the expression of aldehyde oxidase (AOX). AOX could be detected tightly linked to LDs when adipocytes were treated with starvation medium. In addition, the majority of cells show an enormous interconnected, tubulated mitochondria network. Here, we discuss that (1) XOR is involved - together with perilipins - in the secretion of LDs in alveolar epithelial cells of the lactating mammary gland and is important in the transcytosis pathway of capillary endothelial cells. (2) In cells, where LDs are not secreted, XOR cannot be detected at the protein level, whereas in contrast in these cases, AOX is often present. We detect AOX in adipocytes together with perilipins and find evidence that these proteins might direct LDs to mitochondria. Finally, we here report for the first time the exclusive and complementary localization of XOR and AOX in diverse cell types.
\end{abstract}

Keywords Lipid droplets $\cdot$ Perilipins $\cdot$ Mammary gland $\cdot$ Xanthine oxidoreductase $\cdot$ Adipocytes $\cdot$ Aldehyde oxidase

This work is dedicated to Werner W. Franke on the occasion of his 80th birthday.

Parts of this manuscript have been presented with poster contribution at the Cold Spring Harbour Asia Conference on "Lipid Metabolism and Human Metabolic Disorder”, Suzhou, China, June 1-5, 2015: H. Heid, R. Zimbelmann, U. Warnken, M. Schnölzer and S. Rickelt. Revisiting the Formation of Lipid Droplets in Human Adipocytes: Electron Microscopy, Close-up Views and the Expression of Aldehyde Oxidase.

Electronic supplementary material The online version of this article (https://doi.org/10.1007/s00441-019-03152-1) contains supplementary material, which is available to authorized users.

Hans Heid

hans.heid@alumni.dkfz.de

Helmholtz Group for Cell Biology, German Cancer Research Center (DKFZ), Im Neuenheimer Feld 581, Building TP4,

69120 Heidelberg, Germany

2 Present address: David H. Koch Institute for Integrative Cancer Research, Massachusetts Institute of Technology (MIT), Cambridge, MA, USA

$\begin{array}{ll}\begin{array}{l}\text { Abbreviations } \\ \text { abs }\end{array} & \text { Antibodies } \\ \text { AOX } & \text { Aldehyde oxidase } \\ \text { ATGL } & \text { Adipose triglyceride lipase } \\ \text { BTN or BTN1a } & \text { Butyrophilin } \\ \text { EM } & \text { Electron microscopy } \\ \text { ER } & \text { Endoplasmatic reticulum } \\ \text { FA } & \text { Fatty acids } \\ \text { IEM } & \text { Immunoelectron microscopy } \\ \text { IFM } & \text { Immunofluorescence microscopy } \\ \text { LD } & \text { Lipid droplet } \\ \text { MLGM } & \text { Milk lipid globule membrane } \\ \text { MS } & \text { Mass spectrometry } \\ \text { NO } & \text { Nitric oxide } \\ \text { OA } & \text { Oleic acid } \\ \text { OMM } & \text { Outer mitochondrial membrane } \\ \text { PLIN } & \text { Perilipin } \\ \text { PPAR } & \text { Peroxisome proliferator-activated receptor } \\ \text { ROS } & \text { Reactive oxygen species }\end{array}$




$\begin{array}{ll}\text { SDS-PAGE } & \begin{array}{l}\text { Sodium dodecyl sulfate polyacrylamide } \\ \text { gel electrophoresis }\end{array} \\ \text { sLD } & \text { Small lipid droplet } \\ \text { VIM } & \text { Vimentin } \\ \text { XDH } & \text { Xanthine dehydrogenase } \\ \text { XO } & \text { Xanthine oxidase } \\ \text { XOR } & \text { Xanthine oxidoreductase }\end{array}$

\section{Introduction}

In recent years, the origin, the formation and the accumulation of lipid droplets (LDs) in a variety of different cells have been investigated intensely in order to contribute insights to a general problem: obesity as an increasing worldwide major health concern in modern life (Sztalryd and Kimmel 2014). Of particular interest were proteins of the perilipin family bound to LDs (Wang and Sztalryd 2011). The LDs in milk are surrounded by a proteinaceous coat, i.e., the milk lipid globule membrane (MLGM), comprise members of the perilipin family (PLIN2-3), the lactation-specific transmembrane protein butyrophilin (BTN1A) and xanthine oxidoreductase (XOR) as major LD-binding proteins (see Franke et al. 1981; Jarasch et al. 1981; Heid and Keenan 2005). During lactation, the enzyme XOR is involved in the secretion of LDs from the mammary epithelial cells into the mammary gland ducts. This enzyme was also found and localized in capillary endothelial cells (Jarasch et al. 1981; Jarasch et al. 1986; Bruder et al. 1984). In general, XOR regulates cellular redox and detoxification processes, representing an evolutionary old oxidative defense mechanism (Vorbach et al. 2003; Vorbach et al. 2006). $\mathrm{XOR}$ is also reported to be responsible for the final two steps in purine metabolism by converting hypoxanthine to xanthine and xanthine to uric acid with concomitant generation of reactive oxygen species (ROS). Generated ROS products are considered responsible for antimicrobial activity and are involved in various pathological situations (McCord et al. 1985; Berry and Hare 2004; Martin et al. 2004; Battelli et al. 2019).

In LDs isolated from adipocytes, specific protein members of the perilipin family are well established as major LD surface-associated proteins in association with the intermediate filament protein vimentin (Franke et al. 1987; Greenberg et al. 1991; Blanchette-Mackie et al. 1995; Wolins et al. 2005; Heid et al. 2014). Using gene profiling methods and a novel algorithm, XOR was reported (Cheung et al. 2007) as "regulator of adipogenesis and PPARy activity". These striking similarity of sets of LD-associated proteins found in lactating mammary gland cells and in adipocytes prompted us to revisit early adipocyte differentiation in more detail, with special focus on XOR expression.

Here, we show by electron and immunoelectron microscopy new structural details on early droplet formation in cultured human adipocytes. Further, we identify and demonstrate the expression of aldehyde oxidase (AOX) by proteomic and biochemical analysis. We present evidence that AOX is primarily not participating in LD formation and LD packaging during adipogenesis but is involved in lipolysis processes by nutrition deprivation. Implications and possible functions of XOR for packaging and secretion of LDs in the lactating mammary gland versus AOX directing LDs to mitochondria of adipocytes, assisting ordered release of fatty acids for $\beta$-oxidation, are discussed.

\section{Material and methods}

\section{Antibodies and reagents}

The generation of monoclonal (mab) and polyclonal (pab) antibodies (abs) against members of the perilipin family of LD-binding proteins was recently described (Heid et al. 2013). New abs against butyrophilin (BTN1A), xanthine oxidoreductase (XOR) and aldehyde oxidase (AOX) were raised accordingly. These abs are summarized in Table S1 of Supplementary material. Additional abs used for testing and for controls in this study are also listed or given in previous publications (Heid et al. 2013; Heid et al. 2014).

\section{Cell cultures}

Human preadipose cells (Poietics from subcutaneous preadipocytes), growth media and adipocyte differentiation medium (ADM; also named adipocyte induction medium, AIM) - containing insulin, dexamethasone, indomethacin and isobutyl-methylxanthine-were obtained from Lonza (Basel, Switzerland; cat. \# PT-5020, PT-8002 and PT-8202). Cell lysates were obtained as previously described (Heid et al. 2013).

\section{Biochemical methods}

Isolation of MLGM material was according to Franke et al. (Franke et al. 1981). For nitrogen cavitation, density gradient separation, SDS-PAGE, immunoblotting, immunofluorescence microscopy, immunoprecipitation and mass spectrometry analysis, see Heid et al. (2013).

\section{Electron and immunoelectron microscopy}

For electron microscopy (EM), cells were grown on cover slips and fixed as previously described using glutaraldehyde and $\mathrm{OsO}_{4}$-either simultaneously (Franke et al. 1969) or sequentially (Heid et al. 2013). For further details of immunoelectron microscopical techniques, see Franke et al. (1987). 


\section{Results}

\section{Expression of lipid droplet-associated proteins in human mammary gland and in adipocytes}

We compared the proteins described in the literature, which encase LDs, secreted from epithelial cells in lactating mammary gland, with LDs obtained from mesenchymal-derived adipocytes and identified a high similarity of the major proteins (Fig. 1a). The major LD-associated proteins from isolated MLGMs comprise the lactation-specific, transmembrane protein butyrophilin (BTN), the more general LD-binding proteins perilipin 2 and 3 (PLIN2, PLIN3) and xanthine oxidoreductase (XOR). In preadipocytes, in converted and differentiated mature adipocytes, similarly to LDs derived from milk, specific perilipins (PLIN1-4) are associated to LD surfaces. In addition, we wanted to check whether the reported occurrence of XOR in adipocytes (Cheung et al. 2007) following the conversion of preadipocytes to adipocytes (Fig. 1b) is also LD associated. First, the XOR enzyme activity data during adipogenesisreported by Cheung et al. (2007) — were compared with the expression data of perilipins described in our previous observations on adipocytes (Heid et al. 2014) (Fig. 1c).

\section{Selecting suitable antibodies for cultured adipocytes}

In order to test the adipocyte cell system for proper performance of the various antibodies (abs) for correct localization, we used low passages of human preadipocytes (schematically shown in Fig. 1b). Several of the commercial available abs have been proven unspecific and unreliable, e.g., one ab reacted positive in immunoblotting with a band at $27 \mathrm{kD}$, within the reference lane and turned out to be triosephosphate isomerase (Escherichia coli). This protein is completely unrelated to XOR or AOX (see Fig. S5). In recent years, false findings by abs are spread all over the field and the specificity of abs became a matter of intensive debate (Baker 2015). It is evident that proper validation of abs, including eventual crossreactivity and other drawbacks, should be supplied. For example, one report on xanthine oxidase inhibition by febuxostat is stating for used ab only "XO (1:100, Abcam)" and no product number and no further information are given (Yisireyili et al. 2017). Another example with a company statement not very useful on an antigen source ("Peptide internal sequence: considered to be commercially sensitive") is given in Table S1. Therefore, we characterized available XOR abs in parallel to immunofluorescence microscopy (IFM) by immunoblotting and obtained some conflicting and/or negative results (Fig. S5). To overcome this problem, we obtained additional commercial abs and further also generated a series of novel abs (Table S1). We tested and selected 7 different abs specific for PLIN, with 12 different abs specific for XOR and 7 different abs specific for aldehyde oxidase (AOX). Using these abs, we demonstrate exemplarily a wide heterogeneity of LD labeling (Fig. S1).

\section{Electron microscopic studies on the endogenous formation of LDs}

We extended our previous EM and immunelectron microscopy (IEM) studies on adipocytes and adipogenesis (Heid et al. 2014) and found endogenously emergence of very small LDs (sLDs) of forming droplets completely surrounded by vimentin intermediate filaments ("wide space type") (Fig. S2a). The formation and assembly of distinct structures of endoplasmatic reticulum (ER) could be observed (Fig. S2b), structures that approach and encase smaller LDs. In the following steps of growing LDs, the emerging ER tubules, cisternae sheaths and layers were seen interconnected directly with vimentin intermediate filaments at the LDs (Fig. S3a,b). The filaments were arranged in a "high density spacing" modus and mitochondria are kept away from LDs by the intermediate filaments and the ER layers. Multiple ER layers were surrounding and wrapping LDs. The LDs became bigger and bigger in size; they "grow" during these special ER encasements (Fig. 2). Specific situations of ER layers and rare contacts of LDs with mitochondria could also occasionally be seen (Fig. S4a,b).

\section{EM studies of LDs of adipocyte conversion and OA uptake}

Upon addition of oleic acid (OA) to the culture medium, the sheaths of multiple ER cisternae and layers seen in earlier LD formation disappear rapidly. Many, very small microvesicles appear predominantly at the plasma membrane (Fig. 3a). Clusters of vesicle-like structures and invaginations with "rosette" structures, i.e., special spatial arrangements of microvesicles, represent further the high frequency of endocytotic uptake of lipids with the OA treatment (Fig. 3b). Ordered bundles of "high density spacing" vimentin filament surrounding LDs are replaced by loosely LD-attached filaments and "wide space type" filament arrangement; ER layers are fragmented and mitochondria are no more excluded by them and can approach LDs (Fig. 3c).

\section{IEM localization studies of adipocyte conversion and uptake of $O A$}

We next performed IEM localization studies using several of the novel abs (see Table S1) and demonstrated that the rims of ER-derived endogenous LDs in differentiating adipocytes showed a positive reaction for PLIN1. These LDs are loosely associated with bundles of intermediate filaments and at the beginning of conversion, are occasionally contacted by mitochondria (Fig. 4a). Upon addition of OA to the adipocyte 


\section{Milk lipid globule membranes: Preadipocytes and adipocytes:}
1) Butyrophilin (BTN)
2) Perilipin 2 (PLIN 2)
3) Perilipin 3 (PLIN 3)
1) Perilipin 1 (PLIN 1)
2) Perilipin 2 (PLIN 2)
3) Perilipin 3 (PLIN 3)
4) Perilipin 4 (PLIN 4)
4) Xanthine Oxidoreductase (XOR)
5) Xanthine Oxidoreductase $(X O R)^{*}$
*according to Cheung et al., 2007

a
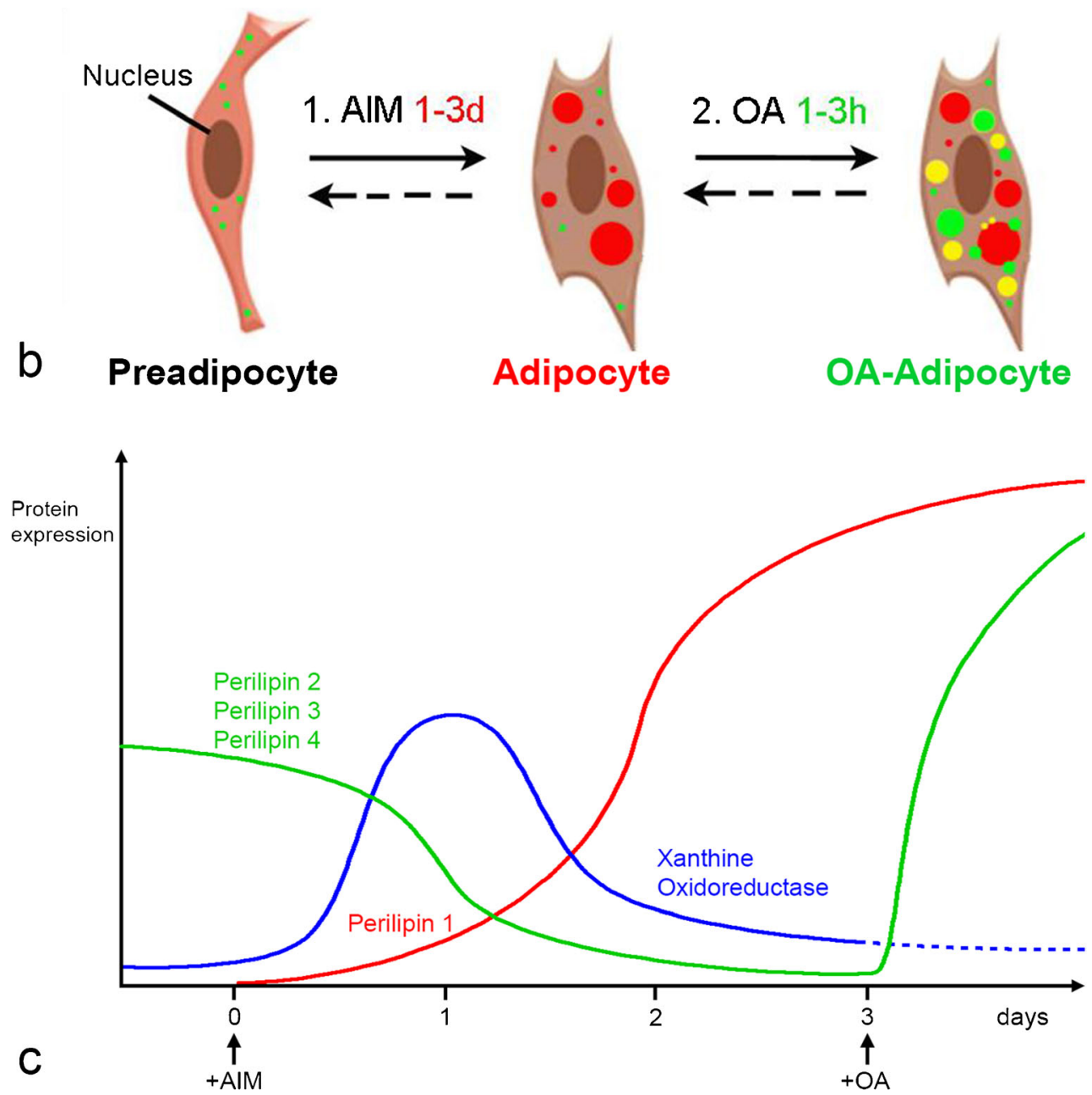

Fig. 1 Comparison of major lipid droplet (LD) binding proteins detected in milk vs. adipocytes, scheme for adipocyte differentiation and expression profile of LD binding proteins during differentiation complemented by reported XOR activity. a LD binding proteins found in epithelial derived milk lipid droplet membranes (MLGM; blue box) and in mesenchymal derived adipocytes (yellow box) are compared. The proteins listed, BTN, PLIN 1-4 and XOR, have been described in literature (for MLGM, see, e.g., Franke et al. 1981; Jarasch et al. 1981; Heid and Keenan 2005; for human adipocytes, see, e.g., Heid et al. 2014). Xanthine oxidase (XOR) activity was reported in adipocytes (Cheung et al. 2007). b Scheme for adipocyte differentiation. Treatments with adipose induction medium (AIM; days (d)) and additionally with oleic acid (OA; hours $(\mathrm{h})$ ) are indicated. Upon stimulation, LDs are

endogenously generated at the endoplasmic reticulum and stained positively for perilipin 1 (PLIN1; red droplets). Other LDs originating mainly from uptake of lipids via an endocytotic process and stain positively for PLIN2-4 (green droplets). Merged droplets, by fusion of different PLIN staining of LDs, appear in yellow. $\mathbf{c}$ Relative expression of LD associated PLIN proteins compared with reported XOR activity during adipocyte differentiation. The profiles in this graph for the PLIN proteins are drawn schematically according to our own data of immunoblotting and of immunofluorescence microscopy experiments (green and red lines). The profile of XOR until "day 3" follows enzyme activity measurements given by Cheung et al. (2007) (blue line). No data on XOR activity are available after OA treatment; therefore, the extrapolation for XOR drawn after day 3 is unknown (dashed blue line)

culture medium, many microvesicle-like structures and a few contacts of LDs and mitochondria are observed (Fig. 4b). IEM

for PLIN2 on differentiating adipocytes reveal several midsize LDs (LD; 200-500 $\mathrm{nm}$ in diameter) and clusters of SLD (50- 


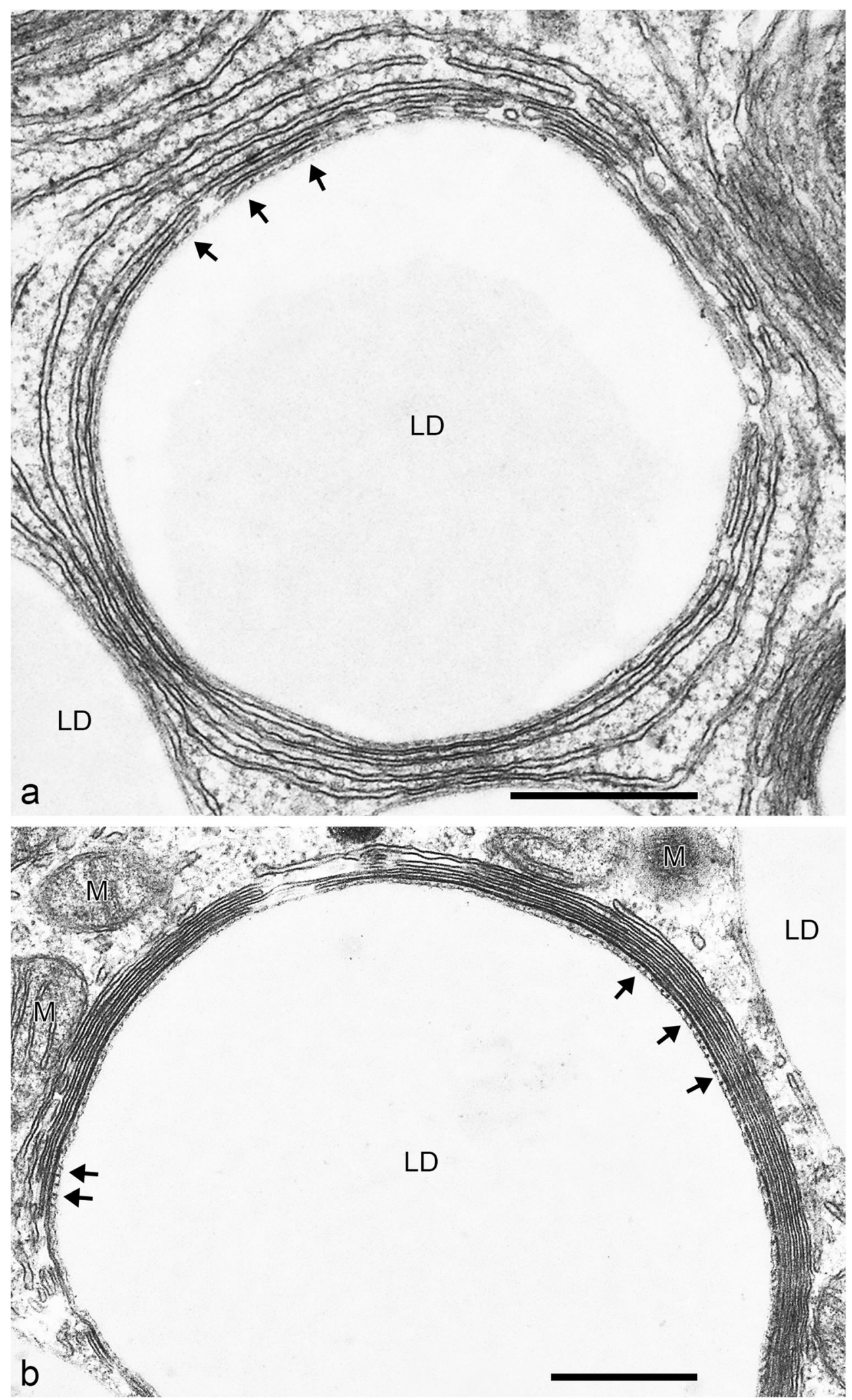

Fig. 2 Electron micrographs showing LDs in human preadipocytes upon stimulation for adipocyte differentiation, revealing multiple staggered endoplasmatic reticulum (ER) layers that encase forming LDs completely. a, b Advanced droplet formation with growing LDs embedded in a dense net of intermediate filaments. Some of these intermediate filaments,

seen in transverse sections, are marked by arrows. Multiple layers of ER cisternae encircle and wrap droplets completely. Examples with four to six ER layers are presented, respectively. LD lipid droplets, M mitochondria. Bars $500 \mathrm{~nm}$ 

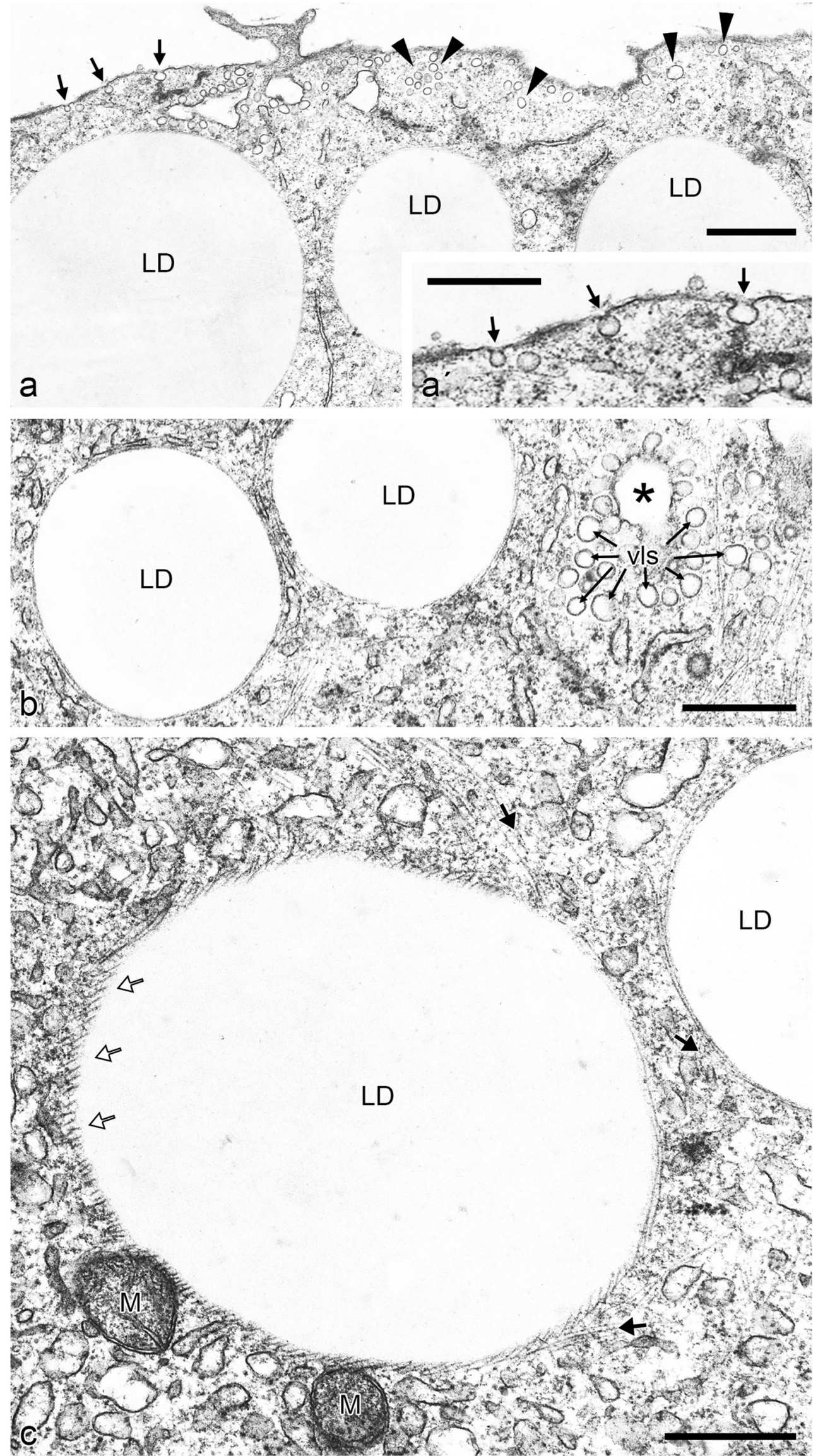
Fig. 3 Electron micrographs showing LDs in human preadipocytes upon adipocyte conversion: additional treatment with oleic acid (OA) leads to many microvesicles and "rosette-like" structures. (a) With OA treatment, many small endocytotic vesicles and invaginations emerge in the cytoplasm near the plasma membrane, greatly increased in number (arrowheads). (a') Three vesicles, seen in (a) in an endocytosis process, are shown in the enlarged insert (arrows). (b) Example of a cluster of vesicle-like structures (here named: vls; arrows) seen besides a rosettelike structure (asterisk) and LDs. "Rosettes" are special spatial compartments, flask-like invaginations of the plasma membrane with regularly arranged mircovesicles. They are involved in exogenous uptake of lipids (see Williamson 1964; Novikoff et al. 1980). (c) The multiple layers of ER cisternae surrounding LDs (also seen in Figs. 2 and S3) disappear upon OA treatment and ordered bundles of intermediate filaments surround LDs as surface-anchored "wide-space type" intermediate filaments (marked by light arrows). Other intermediate filaments connected to LDs and reaching out into the cytoplasm are also marked (black arrows). Some LDs are seen connected via intermediate filaments to mitochondria (M). Bars: (a) $1 \mu \mathrm{m}$ and $\left(\mathrm{a}^{\prime}, \mathrm{b}, \mathrm{c}\right) 500 \mathrm{~nm}$

125-nm sizes in diameter). In addition, most LD and SLD are connected by bundles of intermediate filaments (Fig. 5a). Unlabeled, considerably bigger LDs are seen more often (not shown here). An example of differently distinguishable LDs in adipocytes treated with OA is given for PLIN2 labeling in Fig. 5(b). Upon addition of OA, many microvesicle-like structures can be noticed; however, these invaginations of the plasma membrane are not labeled with PLINs.

\section{Specific oxidases in adipocytes and mammary gland}

We next wanted to confirm the reported occurrence of XOR in adipocytes and tested commercially available abs for XOR, including abs for the homologous protein AOX (Fig. S5). In addition, we raised and characterized several new abs to XOR (Fig. 6a, Table S1). With further characterizations, it became evident that XOR is detectable solely with MLGM, whereas AOX is expressed in adipocytes and not with MLGM (Fig. S6). To confirm these results, we next performed mass spectrometric (MS) analysis and used Coomassie Blue-stained gel bands from MLGM material, from total cell lysate of preadipocytes and from total cell lysate of differentiated adipocytes (Fig. S7). We identified XOR with the MLGM reference sample and additional characteristic LD binding proteins: including BTN1A and PLIN2. In contrast, no XOR was detected in adipocytes; however again, in accordance with our immunoblotting results, the homologous enzyme AOX was identified instead, which has an almost identical molecular mass as XOR. Together with AOX, also PLIN4 and vimentin as known LD binding proteins were identified (Fig. S7).

\section{AOX association with LDs in adipocytes}

AOX is found soluble in the cytoplasm during adipocyte conversion and LD expansion in adipocytes and not associated with LDs (Fig. 6b-d). With starvation condition, EM, density gradient separations and Western blotting, we demonstrate for the first time evidences for AOX-LD association and interaction in immediate vicinity to mitochondria (Fig. 7).

Summarizing our new results obtained with adipocytes regarding association of PLINs and oxidases with LDs (Figs. 4 and 7) and comparing with data on lactating mammary gland cells (Mather and Keenan 1998) and cardiomyocytes (Wang et al. 2011) and from other sources, we recognized a basic and general tethering principle for LD connections to biomembranes (Table 1).

Cartoons of our results with a comparison of major LDassociated proteins detected in mammary gland and in adipocytes are presented in Fig. 8. Whereas PLIN2 and PLIN3 can be detected LD associated in non-lactating and in lactating epithelial cells as well as in mesenchymal preadipocytes and in differentiated adipocytes, PLIN4 is found only in preadipocytes and adipocytes. The transmembrane protein BTN is abundantly expressed only in lactating mammary gland, whereas PLIN1 is detected only in differentiated adipocytes. Oxidases found differ in their location: XOR is found in the mammary gland, AOX in adipocytes. These oxidases are mostly found within the cytoplasm of tissue and cultured cells. Yet XOR is also found LD bound at the inner apical plasma membrane and in secreted milk lipid globules and AOX becomes LD associated by fat depot reduction under starvation conditions in close proximity of mitochondria

\section{Discovery of a complementary localization of XOR and $A O X$}

Finally, so far unknown, when summarizing and comparing former results published on the immunolocalization of XOR with immunohistochemical localization data published for AOX, we discovered an obviously mutually exclusive and complementary localization of these two oxidases in diverse cell types (Table 2). Only capillaries of adipose tissue and not the adipocytes itself express XOR but AOX was found to be present and expressed on the protein level in adipocytes.

\section{Discussion}

The report on XOR in adipose tissue and adipocytes and the postulated involvement of this enzyme in adipogenesis (Cheung et al. 2007) gave rise to revisit and extend our former investigations on the formation of LDs. We found strikingly similar sets of major LD binding proteins reported for MLGs from the lactating mammary gland and for adipocytes. XOR is tethering cytoplasmic LDs in the lactating mammary gland to the apical plasma membrane by interacting with the LD binding protein PLIN2 and the cytoplasmic part of the transmembrane, milk specific protein BTN (Mather and 
Keenan 1998; McManaman et al. 2002; Heid and Keenan 2005; Monks et al. 2016). We wondered what specific role such an enzyme might play in adipocytes, cells that are LD storage cells and not LD secretory cells.

\section{We highlight our major findings}

1. EM and IEM on the formation of LDs in adipocytes are extended and connections of LDs with mitochondria under starvation conditions are presented.

2. We generated novel and reliable abs for XOR and AOX suitable for new experiments.

3. We identified AOX expressed in adipocytes instead of XOR as previously reported.

4. We recognized an exclusive and complementary localization of XOR and AOX in diverse cell types and summarized all the data in tables and cartoons.

5. A hypothesis is presented where XOR together with PLIN2 is tethering LDs to the apical plasma membrane of lactating mammary gland cells and AOX together with PLIN1 is linking LDs with mitochondria in adipocytes under starvation condition.

\section{Is XOR involved in adipogenesis?}

$\mathrm{XOR}$ has been suggested as a novel regulator of adipogenesis (Cheung et al. 2007); however in this report, XOR was not shown at the protein expression level and the XORrelated enzyme AOX was not tested. Like XOR, AOX belongs to a family of molybdo-flavoproteins with an identity towards XOR of $49.7 \%$ on the protein level and with almost a similar molecular mass of $150 \mathrm{kD}$. The genes encoded have almost identical intron/exon organization and both enzymes have a similar spectrum of enzymatic reactions. Therefore, the oxidase activity of XOR activity measurement in the absence and presence of $\mathrm{NAD}^{+}$, claimed to distinguish activities between $\mathrm{XO}$ and $\mathrm{XHD}$, could be prompted also by AOX and oxygen. Current data are based on microarray analysis, activity measurement, a HPLC assay for uric acid levels, working with PPARy agonists, which all can be influenced also by AOX, because both enzymes, XOR and AOX, are able to generate ROS (Kundu et al. 2007; Kundu et al. 2012). In addition, inhibitors like allopurinol and others, used for generating these data, can work on both enzymes and can create misinterpretations (see, e.g., Weidert et al. 2014; Williams et al. 2014). The evolution of AOX from XOR was by gene duplication and the enzymes are vicinally situated on the same chromosome (see, e.g., Krenitsky 1978). Therefore, the claimed cascade of factors that controls adipogenesis might hold true perhaps also for AOX and not exclusively for XOR. To date, many researchers believe that XOR is the principal enzyme responsible for oxidation of purine metabolites to uric acid and that hyperuricemia is highly correlated with increased adiposity, obesity and the metabolic syndrome (Berry and Hare 2004; Harrison 2002; Pacher et al. 2006). Still, the question remains: why could XOR not be shown directly at the protein level in adipocytes? Interestingly, Weigert et al. reported on AOX in high amounts in adipose tissue and mouse 3T3-L1 and demonstrated with fenofibrate, an agonist of PPAR- $\alpha$, reduced AOX protein contents in differentiated 3T3-L1 cells (Weigert et al. 2008).

These different interpretations prompted us to revisit data on adipogenesis with special emphasis on these oxidases XOR and AOX.

\section{Endogenously and exogenously derived LDs in adipocytes and validation of novel antibodies to XOR and AOX}

Human preadipocytes were converted to adipocytes to test commercially available abs for XOR. We wanted to confirm the expression of XOR during adipogenesis in relation to the LD binding perlipins. We took an approach on LD formation and generated two different kinds of LDs (Fig. 1b; described by Heid et al. 2014). We obtained in cells internally generated, endogenous LDs derived from ER with monolayer membranes (Murphy and Vance 1999; Heid and Keenan 2005; Martin and Parton 2006; Wilfling et al. 2013; Choudhary et al. 2015). By addition of albumin-complexed OA to the culture medium, exogenous LDs with bilayer membranes from the uptake via an endocytosis process were additionally generated. By IFM, the huge variety and heterogeneity of resulting LDs by such approaches could be demonstrated (Fig. S1). We discovered using proper abs and by mass spectrometry that instead of the proclaimed XOR, the related enzyme AOX is expressed in adipocytes (see below).

\section{EM findings on vimentin, layers of ER and the formation of LDs}

In a next step, we extended our previous findings on the perilipin-vimentin cortex surrounding nascent LDs (Figs. 2, S2 and S4; see Heid et al. 2014). These structures of forming LDs are often encased by multiple layers of ER. With starting the conversion condition, occasionally some mitochondria seemed to be linked via vimentin intermediate filaments to LDs (Fig. S2b). In general, only a few, small mitochondria are seen in the cytoplasm during LD forming and the perilipin-vimentin cortex and ER layers are keeping the growing LDs separated from mitochondria (Figs. 2 and S3). We would like to emphasize that we and formerly others (Novikoff et al. 1980; Franke et al. 1987; Heid et al. 2014), so far, have not found by EM any evidence yet for LDs contacting microtubules. In support of our findings are results 


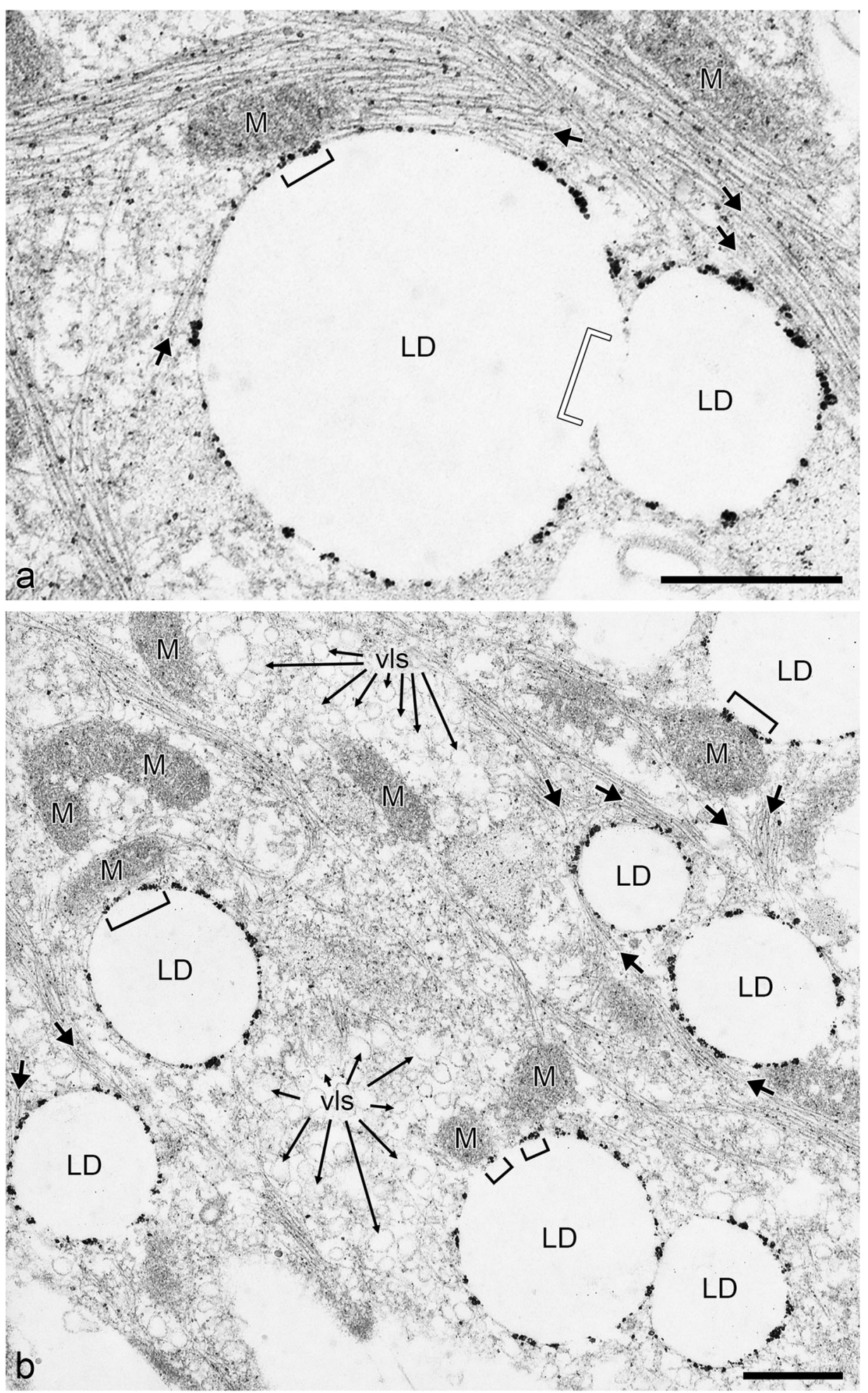

Fig. 4 Immunoelectron microscopic (IEM) localization of PLIN1 in human preadipocytes upon adipocyte conversion, followed by additional treatment with OA. a, b Positive reaction with monoclonal antibody mab Peri112.17 by nanogold labeling and silver enhancement found at the surface of endogenously, ER-derived LDs. These LDs are closely connected by a network of intermediate filaments (bold arrows). a Two LDs shown are in a situation of apparent immediate fusion. Between the adhesion sites of the droplets (large bracket), no structures are detectable, even a simple dot pattern of crosssectioned intermediate filaments is missing. b With OA uptake, prominent plasmalemmal invaginations and smaller vesicle-like structures appear; many are seen in clusters (vls; regular arrows). These are not labeled for PLIN1 and feature no real vesicles inside the cytoplasm but rather originate from crosssectioned invaginations built during uptake of OA. Figure 4(a) shows a very rare situation at the start of adipocyte conversion, an approach of a mitochondrion towards one LD (marked by a small bracket). These special mitochondria-LD contacts are seen in somewhat higher numbers with OA treatment in Fig. 4(b), i.e., when ER layers are suddenly disrupted. M mitochondria. Bars $500 \mathrm{~nm}$ 
Fig. 5 IEM localization of PLIN2 in human preadipocytes upon brief stimulation for adipocyte differentiation, followed by additional treatment with $\mathrm{OA}$. a Using mab AP125, LD labeling is seen mostly at the surface of midsize droplets of several $100 \mathrm{~nm}$ in diameter. Collateral LD-anchored intermediate filaments are marked (bold arrows in Fig. 5a). Clusters of very small, positively labeled droplets can be detected additionally (marked by "sLD"). These tiny droplets are approximately $50-150 \mathrm{~nm}$ in diameter. b Different kinds of droplets can be detected. (1) Many bigger LDs not labeled for PLIN2 (center). (2) Several small and midsize, PLIN2-positive, LDs are occasionally seen just approaching a non-labeled, larger LD for fusion (center). (3) Strongly PLIN2-labeled, newly endocytosed lipid-containing microvesicles, very small LDs (sLD). Many non-labeled, flasklike invaginations of plasma membrane, comprising clusters of vesicle-like structures (vls), can be detected in addition (Fig. 5b). Bars $500 \mathrm{~nm}$

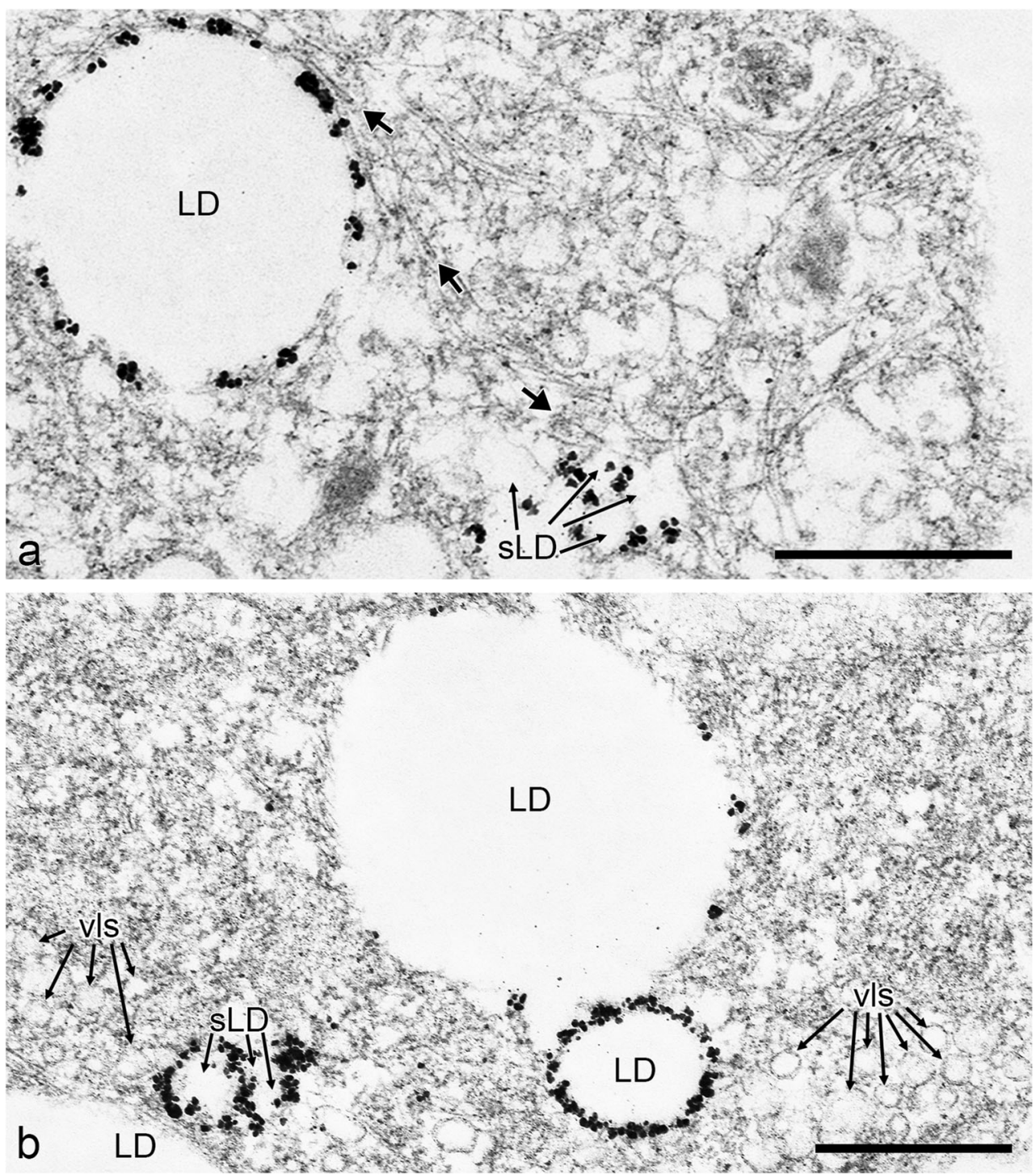

on the ablation of vimentin in steroidogenic tissues where the movement of cholesterol from cytosolic LDs to mitochondria is defected (Shen et al. 2012).

\section{EM and OA uptake}

When albumin-complexed OA was added to the conversion medium of adipocytes (cp. Fig. 1b), almost immediately many endocytotic vesicles and invaginations appear in the cytoplasm, especially near the plasma membrane (Fig. 3a). These endocytotic vesicles have bilayer membranes derived from the plasma membrane material, also seen in clusters of "vesicles-like structures" or of "rosette-like structures" (Fig. $3 b)$. These structures were first described in rat adipose tissue (Williamson 1964) and in mouse 3T3-L1 cultured cells (Novikoff et al. 1980). The invaginations of the plasma membrane are not labeled by perilipin abs. Still in the process of endocytosis, these invaginations are likely be filled with OA cargo. As further consequence of OA supply and "ER decay," the tight intermediate filament structures at the surface of LDs begin to loosen and occasionally, via these vimentin intermediate filaments, mitochondria can be seen linked to individual LDs (Fig. 3c). How bilayer membrane-surrounded, endocytosis-derived LDs can assemble and fuse with monolayer membrane-surrounded, ER-derived LDs, is still a matter of debate. One explanation might be the unique architecture of the "monolayer LDs", which can give rise to "lipidic bridges" (Schuldiner and Bohnert 2017).

\section{IEM localization of perilipins in adipocytes}

IEM localization of PLIN1 upon adipocyte conversion is solely found at the surface of endogenously, ER-derived LDs (Fig. 4). These LDs are connected by a network of intermediate 


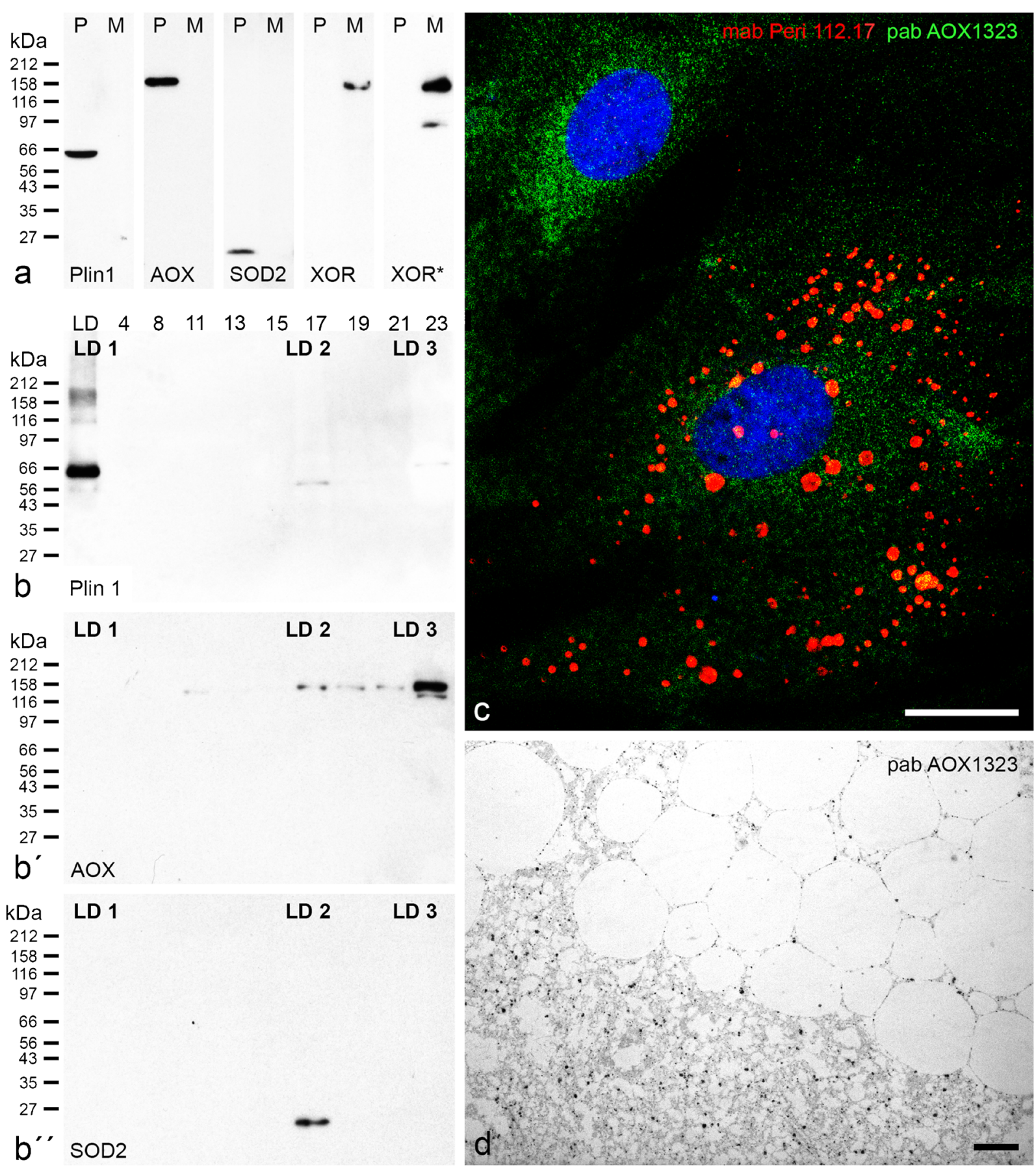

Fig. 6 Biochemical characterization, IFM and IEM localization using human adipocytes and antibodies directed against XOR and AOX. (a) Immunoblotting of total cell lysates of adipocytes differentiated by AIM (lane P) and MLGM from human milk (lane M). Antibodies (abs) tested, respectively, (from left to right): mab Peri112.17 (PLIN1), pab AOX1-hCT-1323 (AOX), pab SOD2 (SOD2), pab hXO-CT-1318 (XO) and pab hXO-CT-1326 (XO*). The antibody specific for AOX reacts only with a $150-\mathrm{kD}$ band of adipocytes. In contrast, at similar molecular weight position, abs for XOR react solely with MLGM material. Control abs PLIN1 and SOD2 react only within the lanes of adipocytes. (b, b $\left.', b^{\prime \prime}\right)$ Density gradient centrifugation separations of AIM-stimulated preadipocytes, followed by immunoblot detection. Selected gradient fractions were tested with mab Peri112.17 (PLIN1) in (b), with pab AOX1-hCT-1323 $(\mathrm{AOX})$ in $\left(\mathrm{b}^{\prime}\right)$ and with pab SOD2 (SOD2) in $\left(\mathrm{b}^{\prime \prime}\right)$. Individual fraction numbers are given at top of (b). For gradient areas LD1 (top layer, fraction of low density),

LD2 (intermediate density) and LD3 (cytosolic fraction, high density), compare our previous publications Heid et al. (2013) and Heid et al. (2014). Positions of molecular weight markers are given at the left margin. PLIN1, AOX and SOD2 are distributed essentially in different gradient areas, respectively. AOX is preferentially detected in the cytosolic fraction LD3, SOD2 in fraction LD2 and not, like PLIN1, in the LD fraction (top layer, LD1). (c) Double immunofluorescence microscopy showing PLIN1 (red) in comparison with AOX (green) staining. (d) Immunoelectron microscopy demonstrating labeling with AOX-specific antibody in the cytoplasm (lower part) and not in the LD region (upper part). No obvious co-localization of PLIN1 and AOX is seen in (c) and the cytoplasmic staining of AOX in (d) fits to the soluble, cytoplasmic occurrence of AOX (fraction LD3) detected in density gradient separation in ( $b^{\prime}$ ), whereas PLIN1 is detected LD bound (fraction LD1). Bars (c) $20 \mu \mathrm{m}$ and (d) $1 \mu \mathrm{m}$ 


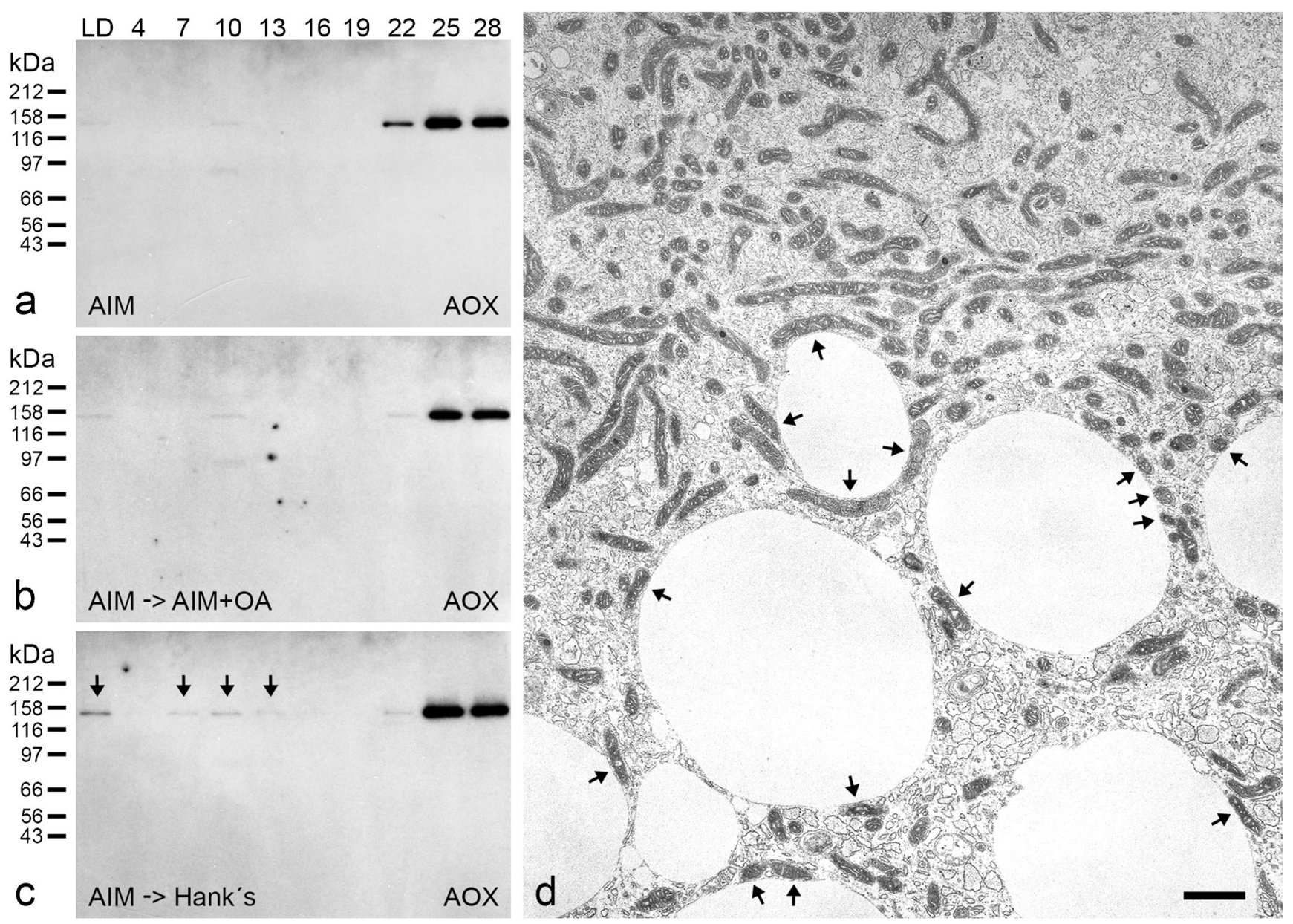

Fig. 7 Immunoblot detection of AOX in differentially treated human adipocytes and electron micrograph of adipocytes subjected to fasting condition. a-c Density gradient centrifugation separations of preadipocytes stimulated by AIM for adipocyte conversion followed by immunoblots using polyclonal antibody specific for AOX (pab AOXhCT-1323). a AIM-treated cells, b AIM-treated cells followed by additional supply of OA and c AIM-treated cells followed by a change of culture cell media for starvation and lipid depletion condition (Hank's media). Individual fraction numbers of the gradient separation are given

filaments. With OA uptake, smaller vesicle-like structures appear in the sections; many are seen in clusters. These are not labeled for PLIN1 but are cross-sectioned invaginations. In addition, possible association sites of mitochondria and LDs with positive labeling of PLIN1 can be detected (Fig. 4, black brackets). These IEM results support an involvement of PLIN1 in tethering mitochondria with LDs (see below for further arguments). IEM localization in adipocytes of PLIN2 is shown in Fig. 5. PLIN2-positive labeling of LDs is seen as a minor population of midsize droplets during adipocyte conversion in midst of PLIN1-positive, bigger LDs. LD anchored by intermediate filaments is clearly detectable. Clusters of very small, positively labeled droplets can be detected additionally ("sLD"). These seem to be derived from endocytosed lipid material by OA treatment. at the top (LD = top layer LD fraction; cp. Fig. 4 shown by Heid et al. 2014). Positions of molecular weight markers are given at the left margins. Positive reaction of fractions 22-28 (cytosolic fractions) can be detected with all treatments. AOX-positive reaction is seen in low and intermediate density LD fractions exclusively with Hank's treatment (Fig. 8(c), arrows). d Electron micrograph of cells as used in Fig. 8c, showing an increase in number of mitochondria, many of them in the immediate vicinity and in very close contact with LDs (arrows). Bar $1 \mu \mathrm{m}$

\section{AOX is expressed in adipocytes and links LDs and mitochondria under nutrition depletion}

Despite testing a panel of abs against XOR with samples of adipocytes, we were not able to confirm the report on XOR on the protein level (Fig. S5). Additional experiments and having identified unambiguously AOX instead of XOR in adipocytes by mass spectrometry (MS) and immunoblotting using a broad spectrum of commercial available and newly generated, validated specific abs (Figs. 6, S6, and S7; Table S1), we wondered why the XOR related enzyme AOX so far was not tested but rather excluded in the work of many reports. So far, only one report describes AOX in high amounts in fat depots and mouse 3T3-L1 cells (Weigert et al. 2008). AOX is known for broad substrate specification used in many clinical studies on the 
Table 1 Linking lipid droplets, perilipins and oxidases to membranes of human cells

\begin{tabular}{llll}
\hline Cell type & LD binding protein & Molybdo-flavoenzyme & Target membrane \\
\hline Epithelial cells of lactating mammary gland & PLIN2 & XOR & Apical PM \\
Adipocytes & PLIN1 & AOX & OMM \\
Myocytes & PLIN5 & AOX & OMM \\
\hline
\end{tabular}

$X O R$ xanthine oxidoreductase, $A O X$ aldehyde oxidase, $P M$ plasma membrane, $O M M$ outer mitochondrial membrane

metabolism of drugs and xenobiotics (Terao et al. 2016; Romao et al. 2017; Beedham 2019). Humans are characterized by a single AOX enzyme, while rodents express four isoenzymes (AOX1-4). Both enzymes AOX and XOR are able to generate besides ROS also nitric oxide (NO) (see Maia and Moura 2018; Bender and Schwarz 2018). Under normal culturing conditions of adipocytes, AOX localizes in the cytoplasm of cells (Fig. 6b-d). XOR is also localized soluble in epithelial cells of the mammary gland (Bruder et al. 1984). In lactating mammary gland epithelial cells, XOR is binding additionally the LD protein PLIN2 and supporting with LDs docking to the apical plasma membrane via BTN. XOR is clustering BTN within the apical membrane and regulates milk lipid secretion into milk ducts (Mather and Keenan 1998; Jeong et al. 2009). This clustering was shown also with mammary specific XOR knockout mice, where XOR was found to make the secretion of LDs highly efficient (Monks et al. 2016). Knowing that a distinct combination of perilipins and molybdo-flavoenzymes - PLIN2 and XOR-is responsible for delivering/transporting LDs to the apical plasma membrane in the lactating mammary gland, we speculate that such a similar tethering system might also exist within adipocytes under starvation condition (Fig. 7). LD trafficking to mitochondria in starved mouse embryonic fibroblasts cells (MEFs) was described recently (Rambold et al. 2015) and thus, we propose for adipocytes a combination of PLIN1 and AOX as a tether for such linkages (Figs. 4 and 7). Adipose triglyceride lipase (ATGL) might also be involved for direct, immediate release of fatty acids (FAs) at the LD-mitochondria interface (Smirnova et al. 2006; Granneman and Moore 2008; Haemmerle et al. 2011; Walch et al. 2015). This assumption awaits verification but some arguments in favor are given by a report with experiments using Saccharomyces cerevisiae (see below; Pu et al. 2011). Direct delivery of FAs from the storage organelle to the degradation/ $\beta$-oxidation organelle would be a highly efficient way to prevent otherwise cytotoxic FA effects in the cytosol. Whether acyl-CoA synthetases (ACSLs) and carnitine palmitoyltransferases (CPTs) (Young et al. 2018; Coleman 2019) play a role as a docking station of outer mitochondria membranes (OMMs) remains to be established. The same holds true also for synaptosomal-associated protein 23 (SNAP23) reported for interaction of LDs and mitochondria (Jagerstrom et al. 2009; Strauss et al. 2016).
LD binding protein PLIN5 of muscle cells is a major player in recruiting LDs to mitochondria (Wang et al. 2011; Andersson et al. 2017; Pribasnig et al. 2018; Gemmink et al. 2018). AOX might be the possible oxidase partner participating together with PLIN5 in linking of LDs to mitochondria in myocytes, because XOR is localized only in capillary endothelial cells of heart and muscle tissue (Jarasch et al. 1981; Jarasch et al. 1986) and AOX is found during myogenesis in the mouse skeletal myoblast cell line $\mathrm{C} 2 \mathrm{C} 12$ (Kamli et al. 2014). A summary of the combinations for perilipins and oxidases tethering LDs to specific membranes is given in Table 1.

\section{Localization of XOR and AOX in cells and tissues}

A surprising finding of our study is the recognition of a complimentary, mutually exclusive localization of the molybdoflavoenzymes XOR and AOX in diverse cell types (Table 2). XOR expression has so far only been reported on the protein level solely in epithelial cells of lactating mammary gland and in capillary endothelial cells of small blood vessels (Jarasch et al. 1981; Jarasch et al. 1986; Bruder et al. 1984). For clinical aspects of endothelial XOR in reperfusion injury and inflammatory signal transduction, see Meneshian and Bulkley (2002). For therapeutic effects of XOR inhibitors in a comprehensive compilation of clinical studies, see Pacher et al. (2006). The many discrepancies currently found in the literature for XOR originate mainly from incorrect addressing and clear discrimination between the two enzymes XOR and AOX. With the knowledge of source and localization of the two enzymes by using proper antibodies, the measurements on purine metabolismanalyzing hypoxanthine and uric acid in blood and urinehave to be credited in most cases rather to AOX than to XOR.

Interestingly, Williams et al. (2014) requested that hundreds of studies using high doses of allopurinol claimed as XO inhibitors should be revisited. Of course, these corrections should be extended also for the localization and antibodybased publications on XOR and AOX. Starting with publicly available reports on the localization of the enzymes (Jarasch et al. 1986; Moriwaki et al. 2001; Weigert et al. 2008), we compared both enzymes (Table 2). Our results now highlight that XOR is not an ubiquitously and constitutively expressed metallo-flavoprotein as stated in most current XOR publications. 


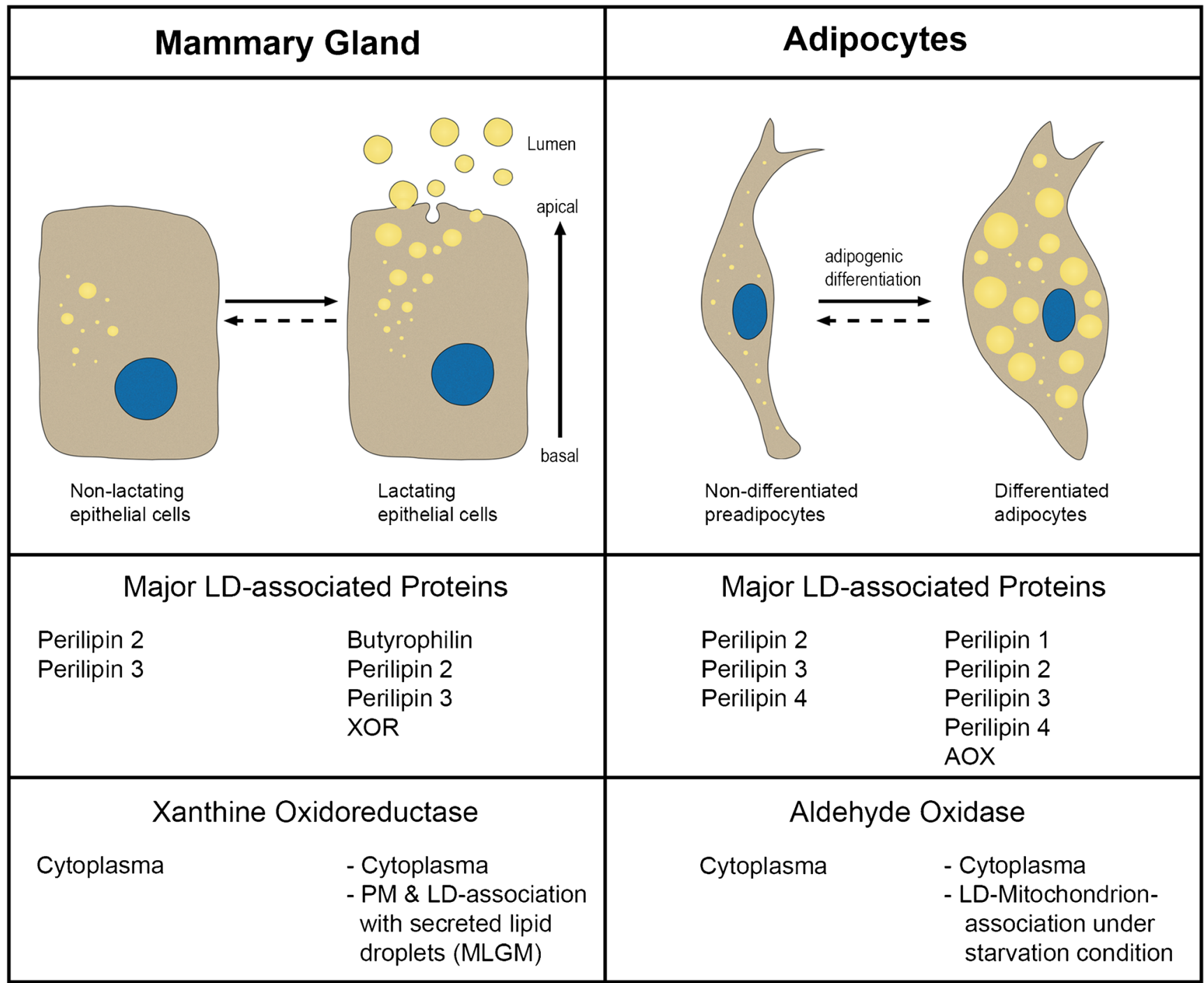

Yellow $=$ Lipid Droplets $($ LDs $) ;$ Blue $=$ Nucleus $; X O R=$ Xanthine Oxidoreductase $; A O X=$ Aldehyde Oxidase $; P M=P l a s m a m e m b r a n e$

Fig. 8 Comparison of major LD-associated proteins and specific oxidases in human mammary gland tissue and adipocytes. LDs in nonlactating and lactating mammary gland as well as in non-differentiated and differentiated adipocytes are schematically presented (two boxes of the upper part). Sets of major LD-binding proteins found under these conditions are listed below (boxes in the middle part). PLIN2 and PLIN3 are expressed in all cases; PLIN4 is detectable in both nondifferentiated and differentiated adipocytes, PLIN1 only in differentiated adipocytes. In lactating mammary gland, the milk-specific transmembrane proteins BTN1A and XOR are major LD-associated proteins. In

\section{Other functions than housekeeping}

XOR and AOX; both enzymes can activate lipid peroxidation. This process generates naturally ROS on a small level in the body. Thereby, polyunsaturated FAs of membranes are attacked and a chain reaction is started. When the antioxidant defense mechanism is overcome, great damage and destruction of membrane lipids could take place. ROS production can change membrane properties and alter membrane deformability. boxes of the lower part of the figure, specific oxidases found with our investigations are summarized, respectively. XOR was expressed strongly in mammary gland. However in contrast to Cheung et al. (2007), XOR could not be confirmed in adipocytes. AOX was found instead. These two different enzymes are localized mainly soluble in the cytoplasm and only seen LD associated in certain situations: (1) XOR at the apical plasma membrane (PM) during milk secretion and at secreted mammary gland milk LDs and (2) AOX in adipocytes under starvation and nutrition depletion conditions at LDs in the neighborhood and contact to mitochondria

XOR has been described as a housekeeping protein with enzymatic functions in purine catabolism and additionally in a variety of other roles. The enzyme has a protective and antimicrobial defense mechanism, can participate in wound healing through effects on ROS production and is supposed to be part of an innate immune system (Jarasch et al. 1986; Vorbach et al. 2002; Vorbach et al. 2003; Vorbach et al. 2006; Madigan et al. 2015). Mouse XOR gene knockout (Vorbach et al. 2002; Ohtsubo et al. 2004; Ohtsubo et al. 2009; Murakami et al. 2014) and mouse isoenzyme AOX4 knockout 
Table 2 Localization of xanthine oxidoreductase and aldehyde oxidase in diverse cell types

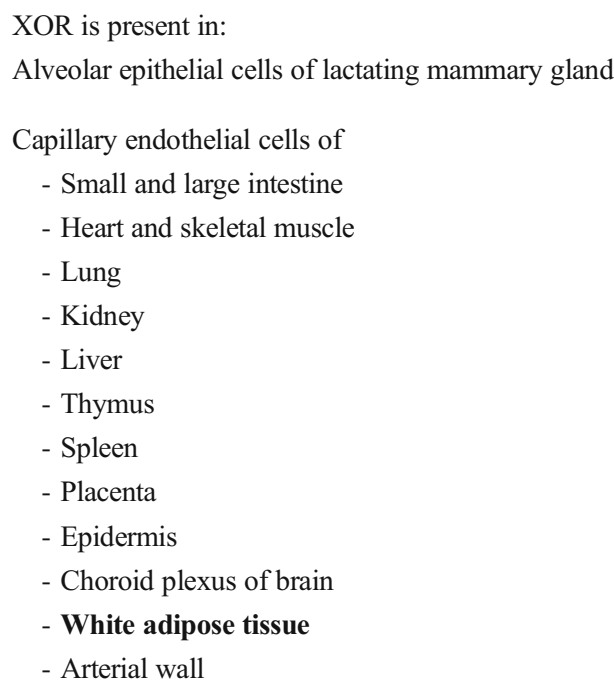

\author{
XOR is absent from: \\ Ductal epithelial cells of mammary gland \\ Myoepithelial cells of mammary and salivary gland \\ Endothelial cells of \\ - Large blood vessels (arteries and veins) \\ - Endocardium \\ - Capillaries of brain (gray and white matter) \\ - Capillaries of testis \\ Epithelial cells of \\ - Liver \\ - Lung \\ - Kidney \\ - Thymus \\ - Epidermis \\ - Intestine \\ Fibroblasts, adipocytes, muscle cells, nerve cells and diverse blood cells
}

\author{
AOX is present in:

Visceral and subcutaneous fat depots
Adipocytes
Liver
Lung
Kidney
Intestine
Prostate
Testis
Adrenal gland

Data on XOR are taken from (1) Jarasch et al., Acta Physiol. Scand (1986) Suppl. 548: 39-46. Data on AOX are taken from (2) Weigert et al., FEBS Letters (2008) 582: 2965-2972. (3) Moriwaki et al., Histol Histopathol (2001) 16: 745-753. Highlighted in bold letters: adipose tissue, fat depots and adipocytes, e.g., one main focus of this manuscript. Data for XOR are taken from a table shown by Jarasch et al. (1986) and originate from bovine tissues. Localizations were confirmed also for human tissues (see Jarasch et al. 1981; Bruder et al. 1984)

studies are beyond the scope of this manuscript and have to be discussed separately. Besides ROS, the generation of NO by the two enzymes, XOR and AOX, should be emphasized (Lundberg et al. 2011; Millar et al. 1998). With its localization in capillary endothelial cells, XOR is a major player and in a key position to control vasodilatation of small vessels by NO and inflammation events by ROS. Blood pressure lowering can also be achieved by allopurinol, an inhibitor of both enzymes, XOR and AOX. This drug is mostly prescribed in gout disease for the reduction of uric acid formation. Using a large clinical data collection of adults with hypertension, allopurinol-treated patients were associated with a significantly lower risk of both stroke and cardiac events than with nonexposed patients (MacIsaac et al. 2016).
In addition to these multiple activities and roles of XOR and AOX, we propose completely new functions, tethering of LDs to biomembranes in conjunction with specific perlipins (Table 1).

$\mathrm{Pu}$ et al. (2011) investigated the interaction between LDs and mitochondria in S. cerevisiae. Using a bimolecular fluorescence complementation assay, they identified an LD protein named Erg6 that can link to mitochondria. Erg6 is described as a regulator of membrane permeability and fluidity (Gaber et al. 1989). With additional Erg6 binding assays, $\mathrm{Pu}$ and coworkers came up with other associated LD proteins. Identified were proteins with sterol esterase activity (Yeh1), with triglyceride lipase activity (Tg13, Tg14) and with oxidoreductase activity (Yor246c). With lipases and the oxidoreductase binding on LDs and Erg6 linking to mitochondria, they 
find - at least viewed from functional aspects - a very similar set of proteins in $S$. cerevisiae as we now propose for human adipocytes. Since early in evolution an oxidoreductase enzyme seems to be important for docking and locally changing membrane properties for proper channeling of lipid products.

Acknowledgments We greatly appreciate Werner W. Franke and Thomas W. Keenan for their continuous generous support and advice for more than 40 years. We especially thank Stefanie Winter, Caecilia Kuhn, Heiderose Schumacher and Edeltraut Noffz (Helmholtz Group for Cell Biology, DKFZ) for valuable help with biochemical characterizations and cell culture work. Special acknowledgement goes to Andrea Janicová (Department Biology, Friedrich-Alexander University of ErlangenNuremberg, Germany) for experiments in the framework of her Master Thesis at the Helmholtz Group for Cell Biology in Heidelberg. Martina Schnoelzer and Uwe Warnken (Functional Proteome Analysis, DKFZ) are gratefully acknowledged for proteomic analysis. We thank Ian Mather (University of Maryland, College Park, MD, USA) for his supply of one XOR antibody and Nicole B. (Heidelberg) for her generous supply of milk used for the isolation of milk lipid globule membranes.

Author contributions Conceived and designed the experiments: HH. Performed the experiments: HH, RZ, YD and SR. Analyzed the data: $\mathrm{HH}$ and SR. Wrote the paper: $\mathrm{HH}$ and SR. Drawings and finalizing figures: $\mathrm{HH}$ and $\mathrm{RZ}$.

Open Access This article is licensed under a Creative Commons Attribution 4.0 International License, which permits use, sharing, adaptation, distribution and reproduction in any medium or format, as long as you give appropriate credit to the original author(s) and the source, provide a link to the Creative Commons licence, and indicate if changes were made. The images or other third party material in this article are included in the article's Creative Commons licence, unless indicated otherwise in a credit line to the material. If material is not included in the article's Creative Commons licence and your intended use is not permitted by statutory regulation or exceeds the permitted use, you will need to obtain permission directly from the copyright holder. To view a copy of this licence, visit http://creativecommons.org/licenses/by/4.0/.

\section{References}

Andersson L, Drevinge C, Mardani I, Dalen KT, Stahlman M, Klevstig M, Lundqvist A, Haugen F, Adiels M, Fogelstrand P, Asin-Cayuela J, Hulten LM, Levin M, Ehrenborg E, Lee YK, Kimmel AR, Boren J, Levin MC (2017) Deficiency in perilipin 5 reduces mitochondrial function and membrane depolarization in mouse hearts. Int $\mathrm{J}$ Biochem Cell Biol 91:9-13

Baker M (2015) Reproducibility crisis: blame it on the antibodies. Nature 521:274-276

Battelli MG, Bortolotti M, Polito L, Bolognesi A (2019) Metabolic syndrome and cancer risk: the role of xanthine oxidoreductase. Redox Biol 21:101070

Beedham C (2019) Aldehyde oxidase; new approaches to old problems. Xenobiotica 1-17. https://doi.org/10.1080/00498254.2019. 1626029

Bender D, Schwarz G (2018) Nitrite-dependent nitric oxide synthesis by molybdenum enzymes. FEBS Lett 592:2126-2139

Berry CE, Hare JM (2004) Xanthine oxidoreductase and cardiovascular disease: molecular mechanisms and pathophysiological implications. J Physiol 555:589-606
Blanchette-Mackie EJ, Dwyer NK, Barber T, Coxey RA, Takeda T, Rondinone CM, Theodorakis JL, Greenberg AS, Londos C (1995) Perilipin is located on the surface layer of intracellular lipid droplets in adipocytes. J Lipid Res 36:1211-1226

Bruder G, Jarasch ED, Heid HW (1984) High concentrations of antibodies to xanthine oxidase in human and animal sera. Molecular characterization. J Clin Invest 74:783-794

Cheung KJ, Tzameli I, Pissios P, Rovira I, Gavrilova O, Ohtsubo T, Chen Z, Finkel T, Flier JS, Friedman JM (2007) Xanthine oxidoreductase is a regulator of adipogenesis and PPARgamma activity. Cell Metab $5: 115-128$

Choudhary V, Ojha N, Golden A, Prinz WA (2015) A conserved family of proteins facilitates nascent lipid droplet budding from the ER. J Cell Biol 211:261-271

Coleman RA (2019) It takes a village: channeling fatty acid metabolism and triacylglycerol formation via protein interactomes. J Lipid Res 60:490-497

Franke WW, Krien S, Brown RM Jr (1969) Simultaneous glutaraldehydeosmium tetroxide fixation with postosmication. An improved fixation procedure for electron microscopy of plant and animal cells. Histochemie 19:162-164

Franke WW, Heid HW, Grund C, Winter S, Freudenstein C, Schmid E, Jarasch ED, Keenan TW (1981) Antibodies to the major insoluble milk fat globule membrane-associated protein: specific location in apical regions of lactating epithelial cells. J Cell Biol 89:485-494

Franke WW, Hergt M, Grund C (1987) Rearrangement of the vimentin cytoskeleton during adipose conversion: formation of an intermediate filament cage around lipid globules. Cell 49:131-141

Gaber RF, Copple DM, Kennedy BK, Vidal M, Bard M (1989) The yeast gene ERG6 is required for normal membrane function but is not essential for biosynthesis of the cell-cycle-sparking sterol. Mol Cell Biol 9:3447-3456

Gemmink A, Daemen S, Kuijpers HJH, Schaart G, Duimel H, LopezIglesias C, van Zandvoort M, Knoops K, Hesselink MKC (2018) Super-resolution microscopy localizes perilipin 5 at lipid dropletmitochondria interaction sites and at lipid droplets juxtaposing to perilipin 2. Biochim Biophys Acta Mol Cell Biol Lipids 1863: 1423-1432

Granneman JG, Moore HP (2008) Location, location: protein trafficking and lipolysis in adipocytes. Trends Endocrinol Metab 19:3-9

Greenberg AS, Egan JJ, Wek SA, Garty NB, Blanchette-Mackie EJ, Londos C (1991) Perilipin, a major hormonally regulated adipocyte-specific phosphoprotein associated with the periphery of lipid storage droplets. J Biol Chem 266:11341-11346

Haemmerle G, Moustafa T, Woelkart G, Buttner S, Schmidt A, van de Weijer T, Hesselink M, Jaeger D, Kienesberger PC, Zierler K, Schreiber R, Eichmann T, Kolb D, Kotzbeck P, Schweiger M, Kumari M, Eder S, Schoiswohl G, Wongsiriroj N, Pollak NM, Radner FP, Preiss-Landl K, Kolbe T, Rulicke T, Pieske B, Trauner M, Lass A, Zimmermann R, Hoefler G, Cinti S, Kershaw EE, Schrauwen P, Madeo F, Mayer B, Zechner R (2011) ATGLmediated fat catabolism regulates cardiac mitochondrial function via PPAR-alpha and PGC-1. Nat Med 17:1076-1085

Harrison R (2002) Structure and function of xanthine oxidoreductase: where are we now? Free Radic Biol Med 33:774-797

Heid HW, Keenan TW (2005) Intracellular origin and secretion of milk fat globules. Eur J Cell Biol 84:245-258

Heid H, Rickelt S, Zimbelmann R, Winter S, Schumacher H, Dorflinger Y (2013) Lipid droplets, perilipins and cytokeratinsunravelled liaisons in epithelium-derived cells. PLoS One 8: e63061

Heid H, Rickelt S, Zimbelmann R, Winter S, Schumacher H, Dorflinger Y, Kuhn C, Franke WW (2014) On the formation of lipid droplets in human adipocytes: the organization of the perilipin-vimentin cortex. PLoS One 9:e90386 
Jagerstrom S, Polesie S, Wickstrom Y, Johansson BR, Schroder HD, Hojlund K, Bostrom P (2009) Lipid droplets interact with mitochondria using SNAP23. Cell Biol Int 33:934-940

Jarasch ED, Grund C, Bruder G, Heid HW, Keenan TW, Franke WW (1981) Localization of xanthine oxidase in mammary-gland epithelium and capillary endothelium. Cell 25:67-82

Jarasch ED, Bruder G, Heid HW (1986) Significance of xanthine oxidase in capillary endothelial cells. Acta Physiol Scand Suppl 548:39-46

Jeong J, Rao AU, Xu J, Ogg SL, Hathout Y, Fenselau C, Mather IH (2009) The PRY/SPRY/B30.2 domain of butyrophilin 1A1 (BTN1A1) binds to xanthine oxidoreductase: implications for the function of BTN1A1 in the mammary gland and other tissues. J Biol Chem 284:22444-22456

Kamli MR, Kim J, Pokharel S, Jan AT, Lee EJ, Choi I (2014) Expressional studies of the aldehyde oxidase (AOX1) gene during myogenic differentiation in $\mathrm{C} 2 \mathrm{C} 12$ cells. Biochem Biophys Res Commun 450:1291-1296

Krenitsky TA (1978) Aldehyde oxidase and xanthine oxidase-functional and evolutionary relationships. Biochem Pharmacol 27:2763-2764

Kundu TK, Hille R, Velayutham M, Zweier JL (2007) Characterization of superoxide production from aldehyde oxidase: an important source of oxidants in biological tissues. Arch Biochem Biophys 460:113121

Kundu TK, Velayutham M, Zweier JL (2012) Aldehyde oxidase functions as a superoxide generating NADH oxidase: an important redox regulated pathway of cellular oxygen radical formation. Biochemistry 51:2930-2939

Lundberg JO, Carlstrom M, Larsen FJ, Weitzberg E (2011) Roles of dietary inorganic nitrate in cardiovascular health and disease. Cardiovasc Res 89:525-532

MacIsaac RL, Salatzki J, Higgins P, Walters MR, Padmanabhan S, Dominiczak AF, Touyz RM, Dawson J (2016) Allopurinol and cardiovascular outcomes in adults with hypertension. Hypertension 67: $535-540$

Madigan MC, McEnaney RM, Shukla AJ, Hong G, Kelley EE, Tarpey MM, Gladwin M, Zuckerbraun BS, Tzeng E (2015) Xanthine oxidoreductase function contributes to normal wound healing. Mol Med 21:313-322

Maia LB, Moura JJG (2018) Putting xanthine oxidoreductase and aldehyde oxidase on the NO metabolism map: nitrite reduction by molybdoenzymes. Redox Biol 19:274-289

Martin S, Parton RG (2006) Lipid droplets: a unified view of a dynamic organelle. Nat Rev Mol Cell Biol 7:373-378

Martin HM, Hancock JT, Salisbury V, Harrison R (2004) Role of xanthine oxidoreductase as an antimicrobial agent. Infect Immun 72:49334939

Mather IH, Keenan TW (1998) Origin and secretion of milk lipids. J Mammary Gland Biol Neoplasia 3:259-273

McCord JM, Roy RS, Schaffer SW (1985) Free radicals and myocardial ischemia. The role of xanthine oxidase. Adv Myocardiol 5:183-189

McManaman JL, Palmer CA, Wright RM, Neville MC (2002) Functional regulation of xanthine oxidoreductase expression and localization in the mouse mammary gland: evidence of a role in lipid secretion. $\mathrm{J}$ Physiol 545:567-579

Meneshian A, Bulkley GB (2002) The physiology of endothelial xanthine oxidase: from urate catabolism to reperfusion injury to inflammatory signal transduction. Microcirculation 9:161-175

Millar TM, Stevens CR, Benjamin N, Eisenthal R, Harrison R, Blake DR (1998) Xanthine oxidoreductase catalyses the reduction of nitrates and nitrite to nitric oxide under hypoxic conditions. FEBS Lett 427: 225-228

Monks J, Dzieciatkowska M, Bales ES, Orlicky DJ, Wright RM, McManaman JL (2016) Xanthine oxidoreductase mediates membrane docking of milk-fat droplets but is not essential for apocrine lipid secretion. J Physiol 594:5899-5921
Moriwaki Y, Yamamoto T, Takahashi S, Tsutsumi Z, Hada T (2001) Widespread cellular distribution of aldehyde oxidase in human tissues found by immunohistochemistry staining. Histol Histopathol $16: 745-753$

Murakami N, Ohtsubo T, Kansui Y, Goto K, Noguchi H, Haga Y, Nakabeppu Y, Matsumura K, Kitazono T (2014) Mice heterozygous for the xanthine oxidoreductase gene facilitate lipid accumulation in adipocytes. Arterioscler Thromb Vasc Biol 34:44-51

Murphy DJ, Vance J (1999) Mechanisms of lipid-body formation. Trends Biochem Sci 24:109-115

Novikoff AB, Novikoff PM, Rosen OM, Rubin CS (1980) Organelle relationships in cultured 3T3-L1 preadipocytes. J Cell Biol 87: 180-196

Ohtsubo T, Rovira II, Starost MF, Liu C, Finkel T (2004) Xanthine oxidoreductase is an endogenous regulator of cyclooxygenase-2. Circ Res 95:1118-1124

Ohtsubo T, Matsumura K, Sakagami K, Fujii K, Tsuruya K, Noguchi H, Rovira II, Finkel T, Iida M (2009) Xanthine oxidoreductase depletion induces renal interstitial fibrosis through aberrant lipid and purine accumulation in renal tubules. Hypertension 54:868-876

Pacher P, Nivorozhkin A, Szabo C (2006) Therapeutic effects of xanthine oxidase inhibitors: renaissance half a century after the discovery of allopurinol. Pharmacol Rev 58:87-114

Pribasnig M, Kien B, Pusch L, Haemmerle G, Zimmermann R, Wolinski $H$ (2018) Extended-resolution imaging of the interaction of lipid droplets and mitochondria. Biochim Biophys Acta Mol Cell Biol Lipids 1863:1285-1296

Pu J, Ha CW, Zhang S, Jung JP, Huh WK, Liu P (2011) Interactomic study on interaction between lipid droplets and mitochondria. Protein Cell 2:487-496

Rambold AS, Cohen S, Lippincott-Schwartz J (2015) Fatty acid trafficking in starved cells: regulation by lipid droplet lipolysis, autophagy, and mitochondrial fusion dynamics. Dev Cell 32:678-692

Romao MJ, Coelho C, Santos-Silva T, Foti A, Terao M, Garattini E, Leimkuhler S (2017) Structural basis for the role of mammalian aldehyde oxidases in the metabolism of drugs and xenobiotics. Curr Opin Chem Biol 37:39-47

Schuldiner M, Bohnert M (2017) A different kind of love-lipid droplet contact sites. Biochim Biophys Acta Mol Cell Biol Lipids 1862: 1188-1196

Shen WJ, Zaidi SK, Patel S, Cortez Y, Ueno M, Azhar R, Azhar S, Kraemer FB (2012) Ablation of vimentin results in defective steroidogenesis. Endocrinology 153:3249-3257

Smirnova E, Goldberg EB, Makarova KS, Lin L, Brown WJ, Jackson CL (2006) ATGL has a key role in lipid droplet/adiposome degradation in mammalian cells. EMBO Rep 7:106-113

Strauss JA, Shaw CS, Bradley H, Wilson OJ, Dorval T, Pilling J, Wagenmakers AJ (2016) Immunofluorescence microscopy of SNAP23 in human skeletal muscle reveals colocalization with plasma membrane, lipid droplets, and mitochondria. Physiol Rep 4(1): e12662. https://doi.org/10.14814/phy2.12662

Sztalryd C, Kimmel AR (2014) Perilipins: lipid droplet coat proteins adapted for tissue-specific energy storage and utilization, and lipid cytoprotection. Biochimie 96:96-101

Terao M, Romao MJ, Leimkuhler S, Bolis M, Fratelli M, Coelho C, Santos-Silva T, Garattini E (2016) Structure and function of mammalian aldehyde oxidases. Arch Toxicol 90:753-780

Vorbach C, Scriven A, Capecchi MR (2002) The housekeeping gene xanthine oxidoreductase is necessary for milk fat droplet enveloping and secretion: gene sharing in the lactating mammary gland. Genes Dev 16:3223-3235

Vorbach C, Harrison R, Capecchi MR (2003) Xanthine oxidoreductase is central to the evolution and function of the innate immune system. Trends Immunol 24:512-517

Vorbach C, Capecchi MR, Penninger JM (2006) Evolution of the mammary gland from the innate immune system? Bioessays 28:606-616 
Walch L, Copic A, Jackson CL (2015) Fatty acid metabolism meets organelle dynamics. Dev Cell 32:657-658

Wang H, Sztalryd C (2011) Oxidative tissue: perilipin 5 links storage with the furnace. Trends Endocrinol Metab 22:197-203

Wang H, Sreenivasan U, Hu H, Saladino A, Polster BM, Lund LM, Gong DW, Stanley WC, Sztalryd C (2011) Perilipin 5, a lipid dropletassociated protein, provides physical and metabolic linkage to mitochondria. J Lipid Res 52:2159-2168

Weidert ER, Schoenborn SO, Cantu-Medellin N, Choughule KV, Jones JP, Kelley EE (2014) Inhibition of xanthine oxidase by the aldehyde oxidase inhibitor raloxifene: implications for identifying molybdopterin nitrite reductases. Nitric Oxide 37:41-45

Weigert J, Neumeier M, Bauer S, Mages W, Schnitzbauer AA, Obed A, Groschl B, Hartmann A, Schaffler A, Aslanidis C, Scholmerich J, Buechler C (2008) Small-interference RNA-mediated knock-down of aldehyde oxidase 1 in 3T3-L1 cells impairs adipogenesis and adiponectin release. FEBS Lett 582:2965-2972

Wilfling F, Wang H, Haas JT, Krahmer N, Gould TJ, Uchida A, Cheng JX, Graham M, Christiano R, Frohlich F, Liu X, Buhman KK, Coleman RA, Bewersdorf J, Farese RV Jr, Walther TC (2013) Triacylglycerol synthesis enzymes mediate lipid droplet growth by relocalizing from the ER to lipid droplets. Dev Cell 24:384-399
Williams CD, McGill MR, Lebofsky M, Bajt ML, Jaeschke H (2014) Protection against acetaminophen-induced liver injury by allopurinol is dependent on aldehyde oxidase-mediated liver preconditioning. Toxicol Appl Pharmacol 274:417-424

Williamson JR (1964) Adipose tissue morphological changes associated with lipid mobilization. J Cell Biol 20:57-74

Wolins NE, Quaynor BK, Skinner JR, Schoenfish MJ, Tzekov A, Bickel PE (2005) S3-12, Adipophilin, and TIP47 package lipid in adipocytes. J Biol Chem 280:19146-19155

Yisireyili M, Hayashi M, Wu H, Uchida Y, Yamamoto K, Kikuchi R, Shoaib Hamrah M, Nakayama T, Wu Cheng X, Matsushita T, Nakamura S, Niwa T, Murohara T, Takeshita K (2017) Xanthine oxidase inhibition by febuxostat attenuates stress-induced hyperuricemia, glucose dysmetabolism, and prothrombotic state in mice. Sci Rep 7:1266

Young PA, Senkal CE, Suchanek AL, Grevengoed TJ, Lin DD, Zhao L, Crunk AE, Klett EL, Fullekrug J, Obeid LM, Coleman RA (2018) Long-chain acyl-CoA synthetase 1 interacts with key proteins that activate and direct fatty acids into niche hepatic pathways. J Biol Chem 293:16724-16740

Publisher's note Springer Nature remains neutral with regard to jurisdictional claims in published maps and institutional affiliations. 